\title{
Iz Aristotelove Politike (6. knjiga)
}

\section{Prevedel Matej Hriberšek}

Pričujoči prevod je del integralnega prevoda Aristotelove Politike, ki bo izšel pri založbi Gospodarski vestnik v zbirki Pravna obzorja. Odlomek je objavljen z dovoljenjem direktorice založbe Vide Šibenik in glavnega urednika zbirke Pravna obzorja akad. prof. dr. Marijana Pavčnika.

11316 b 31 O tem, koliko je torej različic posvetovalnega telesa in vrhovnega organa ustavne ureditve ter o ureditvi oblastvenih funkcij in sodišč, katera [različica] je urejena v skladu s katero ustavno ureditvijo, dalje o propadanju in ohranjanju ustavnih b 35 ureditev, iz katerih razlogov in zaradi katerih vzrokov prihaja do njiju, je bilo povedano že prej.

Ker pa je naneslo, da obstaja več oblik demokracije in podobno tudi drugih ustavnih ureditev, ne bi bilo slabo obenem raziskati tudi, ali je glede teh kaj ostalo [nerazrešeno], ter vsaki [od teh ustavnih ureditev] dodeliti primeren in koristen način [ureditve]. Poleg tega je treba raziskati b 40 kombinacije vseh 1317 a omenjenih [načinov]; ta povezovanja namreč povzročajo, da se ustavne ureditve prekrivajo, tako da aristokracije dobivajo oligarhični značaj, politeje pa bolj demokratičnega. S tem mislim na kombinacije, ki jih je treba raziskati, a za zdaj še niso [bile] raziskane, na primer kadar sta a 5 posvetovalno telo in način izbiranja nosilcev oblastvenih funkcij urejena oligarhično, sodišča pa aristokratično, ali pa, kadar so sodišča in posvetovalno telo urejeni oligarhično, način izbiranja nosilcev oblastvenih funkcij pa aristokratično, ali pa, kadar se na kak drugi način ne združijo vse institucije, a 10 značilne za neko ustavo.

Katera oblika demokracije je torej primerna za katero polis, prav tako pa tudi, katera izmed oligarhij je primerna za katero mnoštvo in katera izmed drugih ustavnih ureditev koristi katerim [državljanom], to je bilo že prej povedano. Vendar pa mora postati jasno ne le, katera izmed teh ustavnih ureditev je najboljša za polis, ampak tudi na kratko pojasnimo, a 15 kako je treba vzpostavljati te in druge [ustavne ureditve]. Najprej se lotimo demokracije, 
kajti obenem bodo jasna tudi dejstva o nasprotni ustavni ureditvi, to pa je tista, ki jo nekateri imenujejo oligarhija.

Za to obravnavo je treba dojeti vse demokratične prvine in prvine, ki a 20 dozdevno spremljajo demokracije; $\mathrm{z}$ združevanjem teh namreč nastajajo [različne] oblike demokracije ter obstaja več kot le ena oblika demokracije, ki so različne.

Obstajata dva vzroka, zakaj je demokracij več. Prvi je prej omenjeni, namreč ljudstva so različna; tu je a 25 mnoštvo poljedelcev, mnoštvo rokodelcev in mnoštvo tetov. In če prvo od teh dodamo drugemu, tretje pa znova prvima dvema, potem se demokracija ne razlikuje samo po tem, da je boljša ali slabša, ampak tudi po tem, da ni več ista. Drugi vzrok je ta, o katerem govorimo zdaj. Prvine, a $30 \mathrm{ki}$ spremljajo demokracije in so dozdevno značilne za to ustavno ureditev, z [različnim] združevanjem ustvarjajo različne oblike demokracije; eno obliko [demokracije] bo spremljalo manj teh prvin, drugo več, tretjo pa vse te.

Koristno pa se je seznaniti s sleherno od teh prvin, bodisi za vzpostavljanje vrste demokracije, ki jo nekdo pač želi, bodisi a 35 za popravke [že obstoječih demokracij]. Snovalci ustavnih ureditev namreč skušajo združiti vse prvine, ki so značilne za temeljno načelo [neke ustave], vendar s takšnim početjem delajo napako, kakor je bilo omenjeno prej, v razpravi o načinih propadanja in načinih ohranjanja ustavnih ureditev.

Zdaj pa obravnavajmo [temeljne] zahteve, značaje [demokratičnih ustav] in cilje, za katerimi stremijo.

2 a 40 Temeljno načelo demokratične ustavne ureditve je torej svoboda (ljudje so namreč vajeni to govoriti, kakor da so samo v tej ustavni 1317 b ureditvi deležni svobode, kajti pravijo, da za tem stremi vsaka demokracija). Ena značilnost svobode je izmenično podrejanje in vladanje. Pravičnost v demokraciji pomeni imeti enakost glede na število in ne glede na zasluženje; in če je to $\mathbf{b} \mathbf{5}$ pravičnost, potem ima mnoštvo nujno vrhovno oblast, in kar večina sklene, to je cilj in to je tisto, kar je pravično. Pravijo namreč, da mora vsak posamezni državljan imeti enak delež, zato v demokracijah prihaja do tega, da imajo nepremožneži več [političnih] pooblastil od premožnežev, kajti tvorijo večino, mnenje večine $\mathbf{b} 10$ pa je odločilno.

To je torej eno znamenje svobode, ki ga vsi demokrati postavljajo kot opredelilo ustavne ureditve. Drugo znamenje je živeti, kakor kdo hoče. Pravijo namreč, da je to naloga svobode, če je res značilnost sužnja, da ne živi, kakor hoče. To pa je drugo opredelilo demokracije: od tod je b 15 izšla zahteva "ne pustiti podrejati se«, še najbolje nikomur, če pa že, potem [se podrejati in vladati] izmenoma; in tako se pripomore $\mathrm{k}$ svobodi, ki temelji na enakosti.

Ob teh osnovah in ob takem počelu so značilnosti demokracije naslednje: nosilce oblastniških funkcij izbirajo vsi izmed vseh; vsi vladajo vsakemu b 20 posamezniku in vsak posameznik izmenoma vlada vsem; oblastniški položaji se določajo z žrebom, in sicer bodisi vsi bodisi tisti, za katere niso potrebne 
izkušnje in strokovno znanje; za opravljanje oblastniških funkcij ni zahtevana nobena premoženjska cenitev, če že, pa kar najmanjša; ista oseba ne more nobene oblastniške funkcije opravljati dvakrat ali malokrat ali pa le redke funkcije, razen tistih, ki so povezane z vojno; oblastniške službe so b 25 kratkotrajne, in sicer ali vse ali pa vse tiste, ki so lahko; sodniško službo opravljajo vsi in [zanjo so voljeni] izmed vseh [državljanov] in za vse [sodne primere] ali pa za najpogostejše, najpomembnejše in najodločilnejše [sodne] zadeve, kot na primer za podajanje zaključnih računov, za ustavne zadeve in zasebne dogovore; ljudska skupščina ima vrhovno oblast nad vsem ali pa nad najpomembnejšimi zadevami, noben oblastveni organ pa nima vrhovne oblasti nad ničemer ali pa b 30 nad kar najmanj zadevami (od organov oblasti je svèt najbolj demokratičen tam, kjer niso na voljo visoke dnevnice za vse; tam, kjer so dnevnice visoke, namreč [ljudje] jemljejo moč tudi temu organu oblasti, kajti če ljudstvo prejema visoke dnevnice, prenaša vse odločitve nase, kakor je bilo omenjeno v prejšnji b 35 obravnavi); dalje [je za demokracijo značilno, da] so vse oblastniške funkcije plačane: ljudska skupščina, sodišča in oblastveni organi, če pa ne [vse], pa [vsaj] oblastveni organi, sodišča, svèt in najpomembnejše skupščine, ali pa med nosilci oblastniških funkcij tisti, ki se morajo udeleževati skupnih obedov. In medtem ko oligarhijo opredeljujejo plemenito poreklo, bogastvo in vzgoja, b 40 se zdi, da so značilnosti demokracije tem ravno nasprotne: neplemenito poreklo, revščina in nevzgojenost. Še to: nobena od oblastniških funkcij ni dosmrtna, 1318 a če pa katera preživi staro spremembo [ustavne ureditve], se njena [politična] moč omeji in izbiro [njenih nosilcev] z glasovanjem nadomesti žreb.

To so torej značilnosti, ki so skupne demokracijam. Iz načela pravičnosti, ki soglasno velja za demokratično a $\mathbf{5}$ (to načelo pa je, da imajo vsi enak delež po številu), izhajata demokracija, ki velja za najbolj pristno demokracijo, in ljudstvo. Enakost namreč pomeni, da nepremožni ne vladajo nič bolj kot premožni in da nimajo sami vrhovne oblasti, ampak jo imajo vsi enako glede na število; [le] tako bi namreč menili, da v a 10 ustavni ureditvi obstajata enakost in svoboda.

3 Naslednje vprašanje je, kako bodo [nepremožni in premožni] dosegli enakost. Ali morajo razdeliti ocenjena premoženja tako, da je premoženje petstotih [premožnih] enako premoženju tisočih [manj premožnih], in mora imeti tisoč [manj premožnih] enako moč kot petsto [premožnih]? Ali pa se enakosti, ki temelji na tem načelu, ne sme vzpostavljati tako, ampak je treba naredili takšno a 15 razdelitev, nato pa vzeti enako število [mož] izmed petstotih in izmed tisočih [državljanov] in jih postaviti za vrhovne pooblaščence nad volitvami [oblastnikov] in nad sodišči? Je torej ta ustavna ureditev najpravičnejša glede na demokratično načelo pravičnosti ali pa gre za ustavno ureditev, ki temelji na številčni premoči? Privrženci demokracije namreč pravijo, da je pravično tisto, kar sklene večina, a 20 privrženci oligarhije pa, da [je pravično] tisto, kar sklenejo lastniki večine imetja, kajti [slednji] pravijo, 
da je treba odločati glede na velikost imetja. Oba primera vključujeta neenakost in krivico, kajti če je pravično tisto, kar sklene peščica ljudi, je to tiranija (če namreč en človek poseduje več od drugih premožnežev, je glede na oligarhično načelo pravičnosti prav, da vlada sam), če pa a 25 je pravično tisto, kar sklene številčna večina, bodo ravnali krivično, ker bodo zaplenjevali premoženje bogatašev, ki so v manjšini, kakor je bilo povedano že prej.

Katera neki bi torej bila enakost, da se bodo o njej strinjali oboji? To je treba raziskati v luči opredelitev pravičnosti, ki jih ponujajo eni in drugi. Pravijo namreč, da mora biti tisto, kar sklene večina državljanov, odločilno. Naj bo torej tako, vendar ne v vseh primerih. a 30 Toda ker je tako, da je polis sestavljena iz dveh delov, in sicer iz bogatašev in revežev, naj bo odločilno tisto, kar sklenejo oboji ali [njihova] večina; če pa so si njihovi sklepi nasprotujoči, naj bo odločilno tisto, kar sklene večina, to je tisti, katerih ocenjeno premoženje je večje. Na primer: če je bogatih deset, revnih pa dvajset in je šest bogatašev sklenilo a 35 ravno nasprotno kot petnajst revežev, so se revežem pridružili štirje bogataši, bogatašem pa pet revežev. Tista skupina torej, katere ocenjeno premoženje je večje, ko se naredi skupni izračun [vrednosti premoženja] obeh skupin, ta skupina mora imeti glavno besedo pri odločanju. Če pa sta obe skupini [številčno] enaki, je to treba šteti za skupno težavo, a 40 kakršna nastopi dandanes, če sta skupščina ali sodišče razdeljena na dva [enaka] dela; 1318 b v takem primeru je treba [o zadevi] odločiti z žrebom ali pa poseči po kakem podobnem ukrepu.

Kar zadeva enakost in pravičnost, pa je, čeprav je zelo težko odkriti resnico o njiju, vendarle to lažje doseči kot pa ljudi, ki so zmožni pridobivati si vedno več, prepričati, [da ju sprejmejo,] kajti enakost in pravičnost vedno b 5 iščejo šibkejši, močnejši pa se zanju prav nič ne zmenijo.

4 Med štirimi oblikami demokracije je najboljša tista, ki je prva po vrsti, kakor je bilo povedano $\mathrm{v}$ predhodnih razpravah; ta je tudi najstarejša med vsemi. Kot prvo jo imenujem glede na to, kakor bi kdo lahko razdelil ljudstva. Najboljše je namreč poljedelsko b 10 ljudstvo, tako da je demokracijo mogoče snovati tam, kjer mnoštvo živi od poljedelstva in pašništva. Ker namreč [mnoštvo] nima veliko imetja, nima prostega časa, zato se skupščinskih zasedanj ne udeležujejo pogosto; in ker nimajo nujnih [življenjskih] potrebščin, so zaposleni s svojimi opravili in ne želijo tujega imetja, ampak jim je delo b 15 prijetnejše od ukvarjanja s politiko in opravljanja javnih funkcij, [vsaj] tam, kjer od političnih funkcij ni velikih dohodkov. Množice namreč bolj stremijo za dobičkom kot za častjo. Dokaz je naslednji. Prenašali so stare tiranije in še vedno prenašajo oligarhije, če jim nihče ne preprečuje delati in jim b 20 ničesar ne jemlje; nekateri med njimi namreč hitro bogatijo, drugi pa ne živijo v pomanjkanju.

Poleg tega dejstvo, da imajo v rokah vrhovni nadzor nad izbiro oblastnikov in polaganjem [njihovih] zaključnih računov, zadovoljuje njihovo potrebo [po časti], če je v njih kaj častihlepnosti, ker v nekaterih demokracijah ljudskim 
množicam zadostuje, da imajo glavno besedo pri posvetovanju, čeprav pri izbiri nosilcev oblastniških funkcij niso soudeleženi [vsi], b 25 ampak samo nekateri, ki so voljeni izmenoma izmed vseh [državljanov], kakor v Mantineji. In tudi to [ustavno ureditev] je treba šteti za neko obliko demokracije, kakršna je bila nekoč v Mantineji.

Zato je za prej omenjeno demokracijo koristno in v njej običajno, da vsi [državljani] izbirajo nosilce oblastniških funkcij, da nadzorujejo podajanje zaključnih računov in b $\mathbf{3 0}$ da razsojajo, da pa najvišje oblastniške funkcije opravljajo možje, izvoljeni na osnovi premoženjskih cenitev (pomembnejše kot so funkcije, višje so [zahtevane] premoženjske cenitve), ali pa da nobena politična funkcija ni pogojena s premoženjskimi cenitvami, ampak jih zasedajo možje, ki so jih sposobni opravljati.

Če možje v polis vodijo tako politiko, jo nujno vodijo dobro (oblastvene položaje bodo namreč vedno zasedali najboljši ob privoljenju ljudstva in b 35 brez zavisti do dobrih državljanov) in taka ureditev nujno zadovoljuje tudi dobre državljane in imenitnike, kajti ne bodo jim vladali slabši od njih in sami bodo vladali pravično, ker drugi nadzorujejo podajanje njihovih zaključnih računov. Koristno je namreč, da je nekdo odvisen [od drugega], in da ne more početi vsega, kar hoče, kajti možnost, b 40 da človek počne, kar hoče, ne more varovati pred zlobo, 1319 a ki je v vsakem človeku. Zato se nujno dogaja tisto, kar je v ustavnih ureditvah najkoristnejše: vladajo dobri državljani, ki ne delajo napak, mnoštvo pa ni za nič prikrajšano.

Da je torej ta najboljša izmed demokracij, je jasno a 5 in tudi vzrok za to: ker ima ljudstvo neko [posebno] kakšnost. Za oblikovanje poljedelskega ljudstva so nekateri izmed zakonov, ki so bili v starih časih v veljavi pri mnogih, izjemno koristni; tako na primer zakon ni dovoljeval posedovanja več zemlje od določene mere, in sicer bodisi na splošno ali pa na prostoru od nekega kraja do trdnjave a 10 ali mesta. V mnogih polis je bilo od davnih časov uzakonjeno, da ni dovoljeno prodajati prvotnih [z žrebom dodeljenih] parcel; obstaja tudi zakon, ki ga pripisujejo Oksilu, in ta ima podobno veljavo: prepoveduje posojanje ob zastavitvi določenega dela zemljišča, ki ga poseduje posameznik. Dandanes pa bi bilo treba obstoječe stanje popraviti z zakonom Afitajcev, a 15 ki je zelo koristen za namen, o katerem govorimo, kajti čeprav je Afitajcev veliko, posedujejo malo zemlje, vendar pa se vsi ukvarjajo s poljedelstvom. Premoženjske cenitve pri njih namreč ne zadevajo celotnih posesti, ampak jih delijo na tako majhne dele, da lahko pri cenitvah premoženja tudi reveži presegajo [minimalni cenzus].

Za poljedelskim mnoštvom a 20 je najboljše tisto ljudstvo, v katerem so [ljudje] pastirji in živijo od [pašne] živine. Njegov način življenja je v mnogih pogledih podoben poljedelstvu, ti so za vojaške naloge zaradi treninga po svojih dispozicijah najbolj izurjeni, telesno pripravni in zmožni živeti pod milim nebom. Skorajda vsa druga mnoštva, iz a 25 katerih so sestavljene demokracije, so dosti slabša od teh; njihov način življenja je slab in nobeno delo, 
s katerim se ukvarja mnoštvo rokodelcev, trgovcev in tetov, ni prav nič povezano $\mathrm{z}$ vrlino, poleg tega se tako rekoč ves ta a $\mathbf{3 0}$ rod zato, ker se kar naprej klati po trgu in po mestu, zlahka udeležuje skupščinskih zasedanj. Poljedelci pa se zaradi raztresenosti po deželi ne sestajajo in tudi ne potrebujejo takega shoda. Kjer pa tudi nanese, da ima ozemlje tako lego, da je [podeželje] daleč od mesta, [tam] je lahko snovati dobro demokracijo in a 35 politejo; ljudstvo je namreč prisiljeno graditi naselbine na poljih, zato se v demokracijah, čeprav obstaja truma trgovcev, skupščinska zasedanja ne smejo sklicevati brez podeželskega mnoštva.

Kako je treba snovati najboljšo in prvo demokracijo, je torej povedano; a 40 jasno pa je tudi, kako je treba [snovati] druge. Treba je namreč sosledno odstopati [od prve in najboljše oblike demokracije] $1319 \mathrm{~b}$ in izločevati vedno hujše mnoštvo.

Skrajne oblike demokracije zato, ker so vsi soudeleženi [v ustavni ureditvi], ne more prenesti vsaka polis in se le težko obdrži, če ni dobro utemeljena $\mathrm{z}$ zakoni in navadami. (O dejavnikih, zaradi katerih prihaja do propadanja te $\mathbf{b}$ 5 in drugih ustavnih ureditev, je bilo že prej povedano večinoma vse.) Za vzpostavljanje takšne demokracije in za krepitev ljudstva voditelji navadno sprejemajo [med državljane] kar največ ljudi in podeljujejo državljanske pravice ne samo zakonitim potomcem, ampak tudi nezakonskim otrokom in tistim, ki imajo samo enega starša b 10 državljana, na primer očeta ali mater. Vsa ta množica se namreč bolj prilega tej obliki demokracije.

Demagogi so torej vajeni tako ravnati, vendar pa bi morali [nove državljane] sprejemati samo toliko časa, dokler množica [številčno] ne preseže imenitnikov in pripadnikov srednjega sloja in te meje ne bi smeli prekoračevati. Kadar so namreč številčno močnejši, b 15 povzročajo v ustavni ureditvi precejšen nered in še dodatno dražijo imenitnike, da stežka prenašajo demokracijo, kar je bilo vzrok vstaje v Kireni, kajti majhno zlo je mogoče spregledati, ko raste, pa bolj bode $\mathrm{v}$ oči.

Poleg tega so b 20 za tako demokracijo koristni tudi taki ukrepi, po kakršnih so posegali Klejsten v Atenah, ko je hotel okrepiti demokracijo, in snovalci demokratične vladavine $\mathrm{v}$ Kireni. Treba je namreč ustanoviti več novih fil in fratrij, združiti zasebne verske obrede v nekaj b 25 javnih ter si izmišljati vse [mogoče], da se vsi [državljani] kar najbolj pomešajo med sabo in da se pretrgajo nekdanji prijateljski odnosi.

Poleg tega se zdi, da vsi za tiranijo značilni ukrepi ustrezajo tudi demokraciji; pri tem imam v mislih na primer neposlušnost sužnjev (ta bi lahko bila do neke mere koristna), žensk in b 30 otrok, ter dovoljevanje, da vsakdo živi, kakor hoče. Podpora takšni ustavni ureditvi bo namreč široka, kajti za ljudske množice je prijetneje, da živijo v neredu kakor pa umerjeno.

$5 \mathrm{Za}$ zakonodajalca in za tiste, ki hočejo snovati takšno ustavno ureditev, pa njena vzpostavitev ni najpomembnejša b 35 in tudi ne edina naloga, ampak prej zagotoviti, da se [ustavna ureditev] ohranja, kajti najsi je ustavna ureditev 
kakršna koli, brez težav traja dan ali dva ali tri. Zato je treba na podlagi prejšnjih raziskav o tem, kateri dejavniki ohranjajo in kateri uničujejo ustavne ureditve, skušati zagotavljati [njeno] varnost, se izogibati dejavnikov, ki jo uničujejo, b 40 in postavljati takšne zakone, tako nenapisane kot 1320 a napisane, ki bodo vsebovali kar največ določil za ohranjanje ustavne ureditve; in ne sme se misliti, da je demokratično ali oligarhično tisto, kar bo povzročilo, da je vladavina $\mathrm{v}$ polis skrajno demokratična ali skrajno oligarhična, ampak tisto, kar bo povzročilo, da se bo ta vladavina ohranila najdlje.

Dandanes pa se a 5 demagogi dobrikajo ljudstvu, zato izvajajo številne zaplembe s pomočjo sodišč. Zato morajo tisti, ki jim je mar za polis, nastopiti proti takemu ravnanju s postavitvijo zakona, da nič, kar je $\mathrm{v}$ lasti obsojencev, ni skupna lastnina in da se ne prenese v državno blagajno, ampak postane sveto. Storilci kaznivih dejanj namreč ne bodo [pri takih ukrepih] nič manj previdni a 10 (kajti kaznovani bodo enako), sodrga pa bo manjkrat glasovala za obsodbo obtožencev, če od tega ne bo imela nobene koristi. Poleg tega morajo vedno skrbeti, da je javnih sodnih procesov kar najmanj, in sicer tako, da s hudimi kaznimi odvračajo tiste, ki vlagajo obtožnice kar na slepo. Navadno sodno ne preganjajo pripadnikov ljudstva, ampak imenitnike, a 15 ustavni ureditvi pa morajo biti, če je le mogoče, naklonjeni vsi državljani; če pa ji že niso vsi, potem vsaj ne smejo svojih vrhovnih oblastnikov šteti za sovražnike.

Ker pa imajo skrajne demokracije številno prebivalstvo in je težko, da bi se [državljani] brez plačila udeleževali skupščinskih zasedanj, takšne okoliščine pa so tam, kjer polis nima [posebnih] dohodkov, pogubne za imenitnike a 20 (tedaj so namreč vir [denarnih sredstev] nujno [izjemna] obdavčitev [premoženja], zaplemba [imetja] in lažne obsodbe, kar je uničilo že mnoge demokracije); kjer torej [polis] nima [posebnih] dohodkov, je le redko treba sklicevati skupščinska zborovanja in na sodiščih mora sodelovati veliko sodnikov, vendar morajo zasedati le malo dni (prednost takega pravila je, a 25 da se bogataši ne bojijo izdatkov, če premožneži ne prejemajo sodniške plače, nepremožni pa jo; prednost pa je tudi, da je razsojanje na sodnih obravnavah dosti boljše, kajti premožneži niso pripravljeni po več dni izostajati od svojih lastnih opravkov, kratek čas pa so pripravljeni).

Kjer pa ima [polis posebne] dohodke, se ne sme početi to, a 30 kar dandanes počnejo demagogi (ti namreč [revežem] razdeljujejo presežke, a takoj, ko jih ti prejmejo, potrebujejo znova isto; takšna pomoč nepremožnim je namreč preluknjan sod).

Toda tisti, ki je pravi demokrat, mora paziti, da mnoštvo ni prerevno, kajti to je vzrok za sprevrženost demokracije. a 35 Izmisliti si je torej treba ukrepe, da bi blagostanje ljudi postalo trajno. Ker pa je to v korist tudi premožnim, morajo kopičiti izkupičke od [posebnih] prihodkov in jih nato zbrane skupaj deliti nepremožnim, zlasti če zmore kdo nakopičiti dovolj, da si pridobi majhno posestevce, če tega ne zmore, pa da dobi osnovna finančna sredstva za zagon trgovine ali $1320 \mathrm{~b}$ poljedelstva. In če to ni mogoče $\mathrm{v}$ korist 
vseh, potem je treba sredstva deliti izmenoma po filah ali kakem drugem delu [prebivalstva], medtem pa morajo premožneži prispevati plačilo za nujne [skupščinske] shode, a so oproščeni nekoristnih liturgij.

Kartažani so si s tako b 5 politiko pridobili prijateljstvo ljudstva; vedno namreč pošiljajo nekatere iz vrst ljudstva v okoliške podrejene naselbine in $s$ tem poskrbijo, da ti obogatijo. Omikani in razumni imenitniki pa zmorejo deliti nepremožne [na skupine], jim dajati osnovna sredstva in jih s tem usmerjati h kaki dejavnosti.

Priporočljivo je tudi posnemati politično taktiko Tarentincev. b $10 \mathrm{Ti}$ si namreč s tem, ko nepremožnim dajejo [svoje] imetje na razpolago za skupno rabo, pridobivajo naklonjenost mnoštva. Poleg tega so za vse oblastniške funkcije uvedli delitev na dve skupini, in sicer se ene dodeljujejo z glasovanjem, druge pa z žrebom; ene se dodeljujejo z žrebom zato, da je ljudstvo lahko udeleženo v njih, druge pa $\mathrm{z}$ glasovanjem zato, da vodijo boljšo politiko. Isto je mogoče doseči tudi b $15 \mathrm{z}$ delitvijo iste oblastniške funkcije, s tem da so eni njeni nosilci izbrani z žrebom, drugi pa z glasovanjem.

Povedano je torej, kako je treba snovati demokracije.

$6 \mathrm{Iz}$ povedanega pa je malodane jasno tudi, kako je treba snovati oligarhije. Sleherno oligarhijo je namreč treba sestavljati iz njenih b 20 nasprotij in jo je pri tem treba primerjati $\mathrm{z}$ nasprotno obliko demokracije; najbolje pomešana in prva pa je ta oligarhija, ki je blizu tako imenovani politeji, v kateri je treba premoženjske cenzuse deliti in določati ene nižje, druge višje; nižje za tiste, ki bodo udeleženi pri nujnih oblastniških funkcijah, b 25 višje pa za tiste, ki bodo udeleženi pri oblastniških funkcijah s širšimi pooblastili. Kdor dosega določeni cenzus, mu mora biti dovoljeno sodelovati v ustavni ureditvi in s cenzusom je treba uvajati tolikšno množico ljudstva, da bodo skupaj z njim [v ustavni ureditvi udeleženi državljani] močnejši od tistih, ki v njej niso udeleženi; vedno pa morajo sodeležnike [v ustavni ureditvi] sprejemati iz boljšega dela ljudstva.

Podobno je treba snovati tudi naslednjo b $\mathbf{3 0}$ oligarhijo, in sicer $\mathrm{z}$ nekaj [dodatnimi] omejitvami.

Kolikor je skrajni demokraciji nasprotna oligarhija, ki je najbolj dinastična in najbolj tiranska med oligarhijami, najslabša, toliko več čuječnosti zahteva. Kakor namreč telesa v dobri zdravstveni kondiciji in kakor plovila, ki so za plovbo b 35 dobro opremljena $\mathrm{z}$ mornarskimi posadkami, dovoljujejo več zmot, ne da bi zaradi njih propadala, medtem ko bolehna telesa in razmajana plovila $\mathrm{z}$ nesposobnimi mornarji ne zmorejo prenašati niti najmanjših napak, tako tudi najslabše ustavne ureditve potrebujejo največ 1321 a čuječnosti.

Demokracije torej na splošno ohranja veliko število ljudi (to je namreč nasprotno pravičnosti, ki temelji na zasluženju), nasprotno pa je jasno, da oligarhija svoj obstoj dolguje dobri ureditvi.

7 a 5 Ker obstajajo štiri glavne skupine mnoštva, in sicer poljedelci, rokodelci, trgovci in teti, obstajajo pa tudi štiri vojaške formacije za uporabo v 
vojni, in sicer konjenica, hopliti, lahkooboroženci in [vojna] mornarica, so tam, kjer je zemljišče primerno za konjenico, naravne razmere primerne za snovanje močne oligarhije a 10 (prebivalcem namreč varnost zagotavlja ta oborožena sila, z vzrejo konj pa se lahko ukvarjajo samo veleposestniki); tam, kjer je [zemljišče primerno] za hoplitsko vojsko, pa so naravne danosti primerne za naslednjo vrsto oligarhije (hoplitsko vojsko namreč sestavljajo bolj premožni kot pa nepremožni), medtem ko sta lahkooborožena vojska in mornarica povsem ljudski.

Kjer je torej a 15 dandanes mnoštvo teh veliko in tam izbruhnejo [notranjepolitične] razprtije, so $\mathrm{v}$ spopadu [oligarhi] pogosto $\mathrm{v}$ podrejenem položaju; kot zdravilo za to je treba poseči po [ukrepu] strategov z veliko vojaškimi izkušnjami, ki konjeniškim in hoplitskim enotam pridružijo primerno število lahkooborožencev. Tako imajo v notranjepolitičnih razprtijah ljudstva premoč a 20 nad premožnimi; ker imajo namreč lahko oborožitev, se zlahka bojujejo proti konjenici in hoplitskim enotam. Ustanavljanje te [oborožene] sile iz takih elementov [za oligarhe] torej pomeni ustanavljanje [oborožene sile] proti samim sebi. Ker pa so razdeljeni po starosti, in sicer na starejše in na mlade, morajo [oligarhi] poskrbeti, da se njihovi sinovi, dokler so še mladi, poučijo a 25 o manevrih lahkih in slabo oboroženih enot, da so potem, ko so izločeni iz starostne skupine otrok, tudi sami mojstri teh [taktičnih] nalog.

Mnoštvu pa je treba omogočiti soudeleženost v vladajočem sloju, in sicer bodisi - kakor je bilo povedano prej - tistim, ki dosegajo določen premoženjski cenzus, bodisi - kakor je v Tebah - tistim, ki so se nekaj časa vzdržali rokodelskih opravil, ali pa a 30 v Masaliji, kjer so izvedli selekcijo med možmi, ki si zaslužijo vključitev v vladajoči sloj, in med tistimi, ki ostanejo zunaj njega.

Poleg tega morajo biti najpomembnejšim oblastniškim funkcijam, ki jih morajo opravljati udeleženi v ustavni ureditvi, naložene liturgije, da ljudstvo rade volje pri njih ni udeleženo in da so razumevajoči do oblastnikov, ker za svojo funkcijo drago a 35 plačujejo. Primerno pa je, da ob nastopu svojih funkcij opravijo veličastne daritve in da zgradijo kako javno poslopje, da ljudstvo, ki se udeležuje [javnih] gostij in vidi mesto okrašeno s kipi in zgradbami, veselo gleda trajnost ustavne ureditve, imenitniki pa bodo a 40 [tako] dobili pomnike svojih [denarnih] izdatkov. Vendar pa nosilci oligarhičnih režimov dandanes tega ne počnejo, ampak prav nasprotno, kajti za dobički se ne pehajo nič manj kot za častjo. Zato bi bilo primerno $1321 \mathrm{~b}$ take [oligarhije] imenovati male demokracije.

Kako je torej treba vzpostavljati demokracije in oligarhije, bodi opredeljeno na opisani način.

$8 \mathrm{~V}$ navezavi na povedano je treba primerno določiti b $5 \mathrm{vse}$, kar je povezano s političnimi funkcijami [in sicer]: koliko jih je, katere so in za kaj so pristojne, kakor je bilo omenjeno tudi prej. Brez nujnih javnih funkcij namreč polis ne more obstajati, brez služb, ki skrbijo za urejenost in red, pa jo je nemogoče dobro upravljati. Poleg tega je nujno, da je v manjših polis manj 
javnih funkcij, v velikih b 10 pa več, kakor je bilo povedano prej; ne sme se torej spregledati, katere funkcije je primerno združevati in katere ločevati.

Prva izmed nujnih [javnih] služb je torej nadzorstvo nad trgom; za nadzor tega mora obstajati neka služba, ki bedi nad trgovinskimi pogodbami in urejenim poslovanjem. Skoraj v vseh b 15 polis je namreč nujno, da [ljudje] ene dobrine kupujejo, druge pa prodajajo, zato da [si] vzajemno zagotavljajo nujne potrebščine, in to je najpriročnejše sredstvo za [doseganje] samozadostnosti, zaradi katere se - tako se dozdeva - [ljudje] zberejo v eno politično skupnost.

Druga služba, ki tej [prvi] sledi in ji je blizu, je nadzorstvo nad javnim in zasebnim imetjem v mestu, da so [na tem področju] b 20 zadeve urejene, vzdrževanje in popravljanje rušečih se zgradb in cest, nadzor nad mejami med posestvi [državljanov], da so [te] neizpodbitne, in vse druge, tem podobne vrste nadzora. Večina to oblastniško funkcijo imenuje mestno nadzorstvo, ima pa več oddelkov b 25 in v polis $z$ večjim številom prebivalstva za vodje različnih oddelkov postavljajo različne oblastnike, na primer nadzornike obzidja, nadzorovalce izvirov in pristaniške čuvaje.

Tu je še druga nujna služba, ki je slednji zelo podobna; ima namreč enaka pooblastila, vendar na podeželju in nad zadevami zunaj mesta. Te oblastnike eni imenujejo b 30 nadzorniki podeželja, drugi pa nadzorniki gozdov.

To so torej tri [nadzorniške] službe nad temi zadevami; obstaja pa še neka druga oblastniška služba, h kateri se stekajo skupni dohodki, ti uradniki jih varujejo in razdeljujejo slehernemu oddelku uprave polis. Te [oblastnike ljudje] imenujejo davkarji in zakladniki.

Spet druga je oblastniška služba, pri kateri je treba knjižiti zasebne b 35 pogodbe in sodbe [s] sodišč; pri teh istih oblastnikih pa je treba vlagati obtožnice in izvesti uvodne postopke [v sodne procese]. Ponekod tudi to službo delijo na več oddelkov, drugod pa obstaja ena [sama], ki ima vrhovna pooblastila nad vsemi omenjenimi zadevami; njene nosilce imenujejo sveti arhivarji, predstojniki, arhivarji in $\mathrm{z}$ drugimi, b 40 tem podobnimi nazivi.

Tej sledi skoraj najnujnejša in najtežja od vseh oblastniških služb, in sicer ta, ki skrbi za izvrševanje kazni nad obsojenci, izterjevanje denarja od tistih, katerih imena so objavljena, ker so vpisani na 1322 a sezname javnih dolžnikov, in straženje zapornikov. Ta služba je težavna zato, ker je zelo osovražena, tako da tam, kjer [njeni nosilci] od nje ne morejo imeti velikega dobička, ljudje te službe niso pripravljeni sprejeti, če jo že sprejmejo, pa je niso pripravljeni opravljati v skladu z zakoni. a 5 A ta služba je nujna, ker ni prav nobene koristi od tega, da sodni procesi o vprašanjih pravice sicer potekajo, vendar pa ne dosegajo svojega cilja; in če ljudje ne morejo živeti v skupnosti tam, kjer ni sodnih procesov, tudi tam ne morejo živeti v skupnosti, kjer se kazni ne izvršujejo. Zato je bolje, da ta oblastniška služba ni ena, ampak da jo opravljajo različni [pooblaščenci] z različnih sodišč; in prav tako je treba skušati razdeljevati [naloge], ko gre za javne objave a 10 [posameznikov,] vpisanih na seznam javnih dolžnikov. Poleg tega je bolje, da nekatere kazni izvršujejo tudi 
nosilci drugih funkcij, še posebej, da novi nosilci te funkcije izvršujejo tiste kazni, ki so jih naložili njihovi predhodniki; in kar zadeva kazni, je bolje, da od nosilcev funkcij, ki so trenutno na položaju, eden kazni izreče, drugi pa jih izvršuje. Tako na primer naj mestni nadzorniki izvršujejo kazni, ki jih naložijo tržni nadzorniki, kazni, ki jih naložijo mestni nadzorniki, pa naj izvršujejo drugi oblastniki. a 15 Čim manj bodo izvrševalci kazni osovraženi, tem bolj bodo izvršitve kazni dosegle svoj cilj. Če isti posamezniki izrečejo obsodbo in izvršujejo kazen, so dvojno osovraženi; če pa nastopajo isti posamezniki v obeh vlogah v vseh primerih, to iz njih naredi sovražnike vseh.

V mnogih polis je pazniška služba ločena od službe, ki izvršuje kazni; a 20 tak primer je tako imenovana enajsterica $v$ Atenah. Zato je bolje tudi to funkcijo ločevati in iskati domiseln ukrep tudi zanjo. Ta ni namreč nič manj nujna od [prej] omenjene, a izkušnje kažejo, da se pošteni ljudje tej funkciji najbolj izogibajo, da pa nadzora nad njo ni varno zaupati malopridnežem kajti ti sami a 25 bolj potrebujejo stražo, kot pa so zmožni stražiti druge. Zato za čuvanje zapornikov ne sme biti dodeljena ena [sama] politična instanca in tudi ne ena neprenehoma, ampak morajo to službo izmenoma opravljati enkrat različni mladci (tam, kjer obstaja enota vojaških obveznikov ali stražarjev), drugič pa različni nosilci oblastniških funkcij.

Te oblastniške a 30 funkcije je torej treba postaviti na prvo mesto kot najnujnejše, za njimi pa tiste, ki niso nič manj nujne, a so še višje stopnje, saj je zanje potrebno veliko izkušenosti in zanesljivosti. Takšne bi bile službe, ki jim je zaupano varovanje polis, in službe, ki so odgovorne za vojaške potrebe. Tako v času a 35 miru kot tudi v času vojne so enako potrebni nadzorniki straže [mestnih] vrat in obzidja, [vojaškega] nabora in taktičnega razporejanja državljanov. V nekaterih polis obstaja za opravljanje vseh teh nalog več uradnih funkcij, v drugih manj; tako je na primer v majhnih polis 1322 b ena zadolžena za vse te naloge. Nosilce teh funkcij imenujejo strategi in polemarhi. Poleg tega, če obstajajo konjeniki ali lahkooboroženci ali lokostrelci ali [vojna] mornarica, je tudi na čelo sleherne od teh vojaških enot postavljena vodilna funkcija; te imenujemo navarhije, hiparhije in taksiarhije, njim podrejene manjše [poveljniške] funkcije pa trierarhije, lohagije $\mathbf{b} 5$ in filarhije ter podobno vse njihove pododdelke. Celota teh [dolžnosti] tvori eno samo vrsto [javnih funkcij v polis]: službo nadzorništva nad vojnimi zadevami. Tako je torej s to oblastniško funkcijo.

Ker pa nekatere od vodilnih funkcij, če ne vse, upravljajo velike vsote javnih [finančnih] sredstev, mora obstajati tudi neka druga služba, ki bo pregledala račune in vrh tega sprejela zaključni račun, b 10 sama pa se ne ukvarja $\mathrm{z}$ ničimer drugim. Nosilce te funkcije eni imenujejo overitelji zaključnih računov, drugi [javni] računovodje, tretji finančni nadzorniki, četrti javni zagovorniki.

Poleg vseh teh javnih funkcij obstaja tudi politična funkcija, ki ima suvereno oblast nad vsemi: $\mathrm{v}$ domeni te je namreč pogosto izvedba in uvedba [kakega ukrepa] ali pa predseduje ljudski skupščini [v tistih polis], kjer ima 
vrhovno oblast b 15 ljudstvo, kajti obstajati mora tudi organ, ki sklicuje [na skupščinsko zasedanje] najvišje telo oblasti v ustavni ureditvi. Ponekod to telo imenujejo prèdsvétniki, ker se predhodno posvetujejo, tam, kjer je oblast $\mathrm{v}$ rokah mnoštva, pa ga raje imenujejo svèt.

To so torej skoraj vse politične funkcije. Druga vrsta nadzorniške službe skrbi za bogočastje; [takšni funkciji sta] na primer svečeniki in upravitelji b 20 svetišč, ki skrbijo za ohranjanje obstoječih poslopij, za popravljanje propadajočih stavb in vse drugo, kar je namenjeno bogoslužju. Ponekod se zgodi, da je takšna nadzorna služba samo ena, kot na primer v majhnih polis, drugod pa jih je veliko in so ločene od svečeništva, kot so na primer vodje b 25 darovanj, čuvaji svetišč in zakladniki svetega premoženja. Neposredno na to se navezuje posebna služba, ki je ločena za opravljanje vseh skupnih žrtvovanj, ki niso zakonsko dodeljena svečenikom, ampak njihovo dostojanstvo izvira s skupnega ognjišča; nosilce te funkcije eni imenujejo arhonti, drugi kralji, tretji pritani.

b 30 Nujne nadzorne službe torej - če na kratko povzamemo - skrbijo za naslednja področja: verske zadeve, vojskovanje, [državne] dohodke in izdatke, trg, mesto, pristanišča in podeželje; dalje sodišča, vknjižbe [zasebnih] pogodb, b 35 izvršitve kazni, straženje zapornikov, javno računovodstvo, finančni nadzor oblastnikov in sprejemanje [njihovih] zaključnih računov ter končno za funkcije, povezane $\mathrm{z}$ ustanovo, ki se posvetuje o javnih zadevah.

Funkcije, značilne za polis, ki uživajo več prostega časa, ki bolj uspevajo, vrh tega pa skrbijo b 40 za urejenost, so: nadzorstvo nad ženskami, varstvo zakonov, nadzorstvo nad otroki in 1323 a nadzorstvo gimnazijev, poleg teh pa še nadzorna služba, pristojna za gimnična in dionizična tekmovanja ter vse druge tovrstne predstave. Nekatere od teh javnih funkcij očitno niso demokratične, na primer nadzorstvo nad ženskami in nadzorstvo otrok; a 5 nepremožni so namreč zaradi pomanjkanja sužnjev prisiljeni uporabljati ženske in otroke kot služabnike.

Od treh političnih funkcij, ki v nekaterih polis dajejo smernice za izbiro oblastnikov z najvišjimi pooblastili (in sicer so to varuhi zakonov, prèdsvétniki in svèt), so varuhi zakonov aristokratska ustanova, prèdsvétniki oligarhična, svèt pa demokratična.

Nekako v grobih potezah a 10 smo torej spregovorili o skoraj vseh javnih funkcijah. 